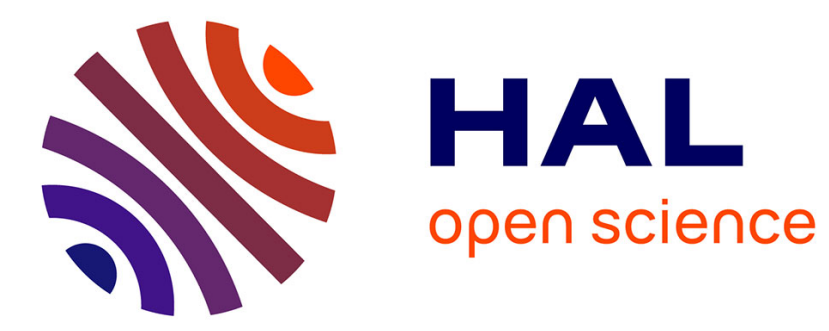

\title{
Long-term mortality and vascular event risk after aneurysmal subarachnoid hemorrhage
}

Marieke Jh Wermer, Paut Greebe, Ale Algra, Gabriel J.E. Rinkel

\section{To cite this version:}

Marieke Jh Wermer, Paut Greebe, Ale Algra, Gabriel J.E. Rinkel. Long-term mortality and vascular event risk after aneurysmal subarachnoid hemorrhage. Journal of Neurology, Neurosurgery and Psychiatry, 2009, 80 (12), pp.1399. 10.1136/jnnp.2008.157586 . hal-00552714

\section{HAL Id: hal-00552714 https://hal.science/hal-00552714}

Submitted on 6 Jan 2011

HAL is a multi-disciplinary open access archive for the deposit and dissemination of scientific research documents, whether they are published or not. The documents may come from teaching and research institutions in France or abroad, or from public or private research centers.
L'archive ouverte pluridisciplinaire $\mathbf{H A L}$, est destinée au dépôt et à la diffusion de documents scientifiques de niveau recherche, publiés ou non, émanant des établissements d'enseignement et de recherche français ou étrangers, des laboratoires publics ou privés. 


\section{Long-term mortality and vascular event risk after aneurysmal subarachnoid haemorrhage}

Marieke J.H. Wermer MD ${ }^{1}$, Paut Greebe $\mathrm{RN}^{1}$, Ale Algra MD ${ }^{1,2}$ and Gabriël J.E. Rinkel MD ${ }^{1}$

From the ${ }^{1}$ Departments of Neurology and Neurosurgery, Rudolf Magnus Institute of Neuroscience,

and the ${ }^{2}$ Julius Centre for Health Sciences and Primary Care, University Medical Centre, Utrecht, The Netherlands

\section{Correspondence to:}

M.J.H. Wermer, MD, Department of Neurology: G03.228

University Medical Centre Utrecht, Heidelberglaan 100

3500 GA Utrecht, The Netherlands

Tel: +31-30-2507975, Fax: +31-30-2542100, email: m.wermer@umcutrecht.nl

Disclosures: The authors report no conflicts of interest

Word count: 1449

Key terms: subarachnoid haemorrhage, mortality, aneurysm, stroke, epidemiology 


\begin{abstract}
Background: Patients with a history of SAH may be at risk for vascular events and excess mortality.

Methods: We interviewed 752 patients (mean age 50 years, 67\% women, mean follow-up 8.1 years) clipped between 1985 and 2001 after SAH who had been discharged home or to a rehabilitation facility about new vascular events. We compared age- and sex-specific mortality after SAH with that of the general population by standardized mortality ratios (SMR). The incidence of vascular events in SAH patients was compared with that in patients after TIA or minor stroke.

Results: The SMR for SAH patients was 1.7 (95\%CI 1.4-2.1) overall and 3.2 (95\%CI 0.8-13.1) for patients $<40$ years. In the first 10 years after SAH the cumulative incidence of a vascular event was $11.2 \%$ (95\%CI 7.0-14.4), which was lower (HR 0.43, 95\%CI 0.33-0.57) than that in patients with a minor stroke.
\end{abstract}

Conclusion: SAH patients who recover to a functional independent state have an excess mortality compared with the general population. The risk of vascular events after SAH is lower than after minor stroke, but higher than the population risks reported in the literature. 


\section{INTRODUCTION}

Patients who recover after subarachnoid haemorrhage (SAH) with successful occlusion of the ruptured aneurysm are believed to have a long-term outcome comparable to persons without a history of SAH. However, former SAH patients are at risk of recurrent SAH from newly developed aneurysms.[1] Furthermore, hypertension and smoking are not only risk factors for SAH but for vascular diseases in general.[2] SAH patients might, therefore, have a reduced life-expectancy. We

studied the standardized mortality ratios (SMR) and the incidence of vascular events other than recurrent SAH in a large cohort of clipped patients who regained independence after SAH. 


\section{PATIENTS AND METHODS}

From a prospectively collected database of SAH patients admitted to the University Medical Centre Utrecht we included all patients admitted between 1985 and 2001 meeting the following criteria: SAH confirmed by CT or lumbar puncture; presence of an aneurysm; clipping of all detected aneurysms; age at time of $\mathrm{SAH} \geq 20$ years and discharge to home or a rehabilitation facility. After approval of the hospital ethical committee we contacted the general practitioner of all eligible patients on survival status. If a patient had died we asked for the cause of death. We invited patients $<70$ years to the outpatient clinic by a letter; older patients were contacted by telephone. We asked the patients about new vascular events other than recurrent SAH with a standardized interview.

\section{Data-analysis Standardized Mortality Ratios}

We registered the number of patients who had died during follow-up (all causes). We used Standardized Mortality Ratios (SMR) to investigate excess mortality in SAH patients compared with the general population. Population based statistics of The Netherlands were used as reference for calculation of the expected number of deaths.[3] Person-years of our cohort were calculated for sex and age (5-year) strata. We adjusted for patients who changed from age stratum during follow up. The expected number of deaths in our cohort was calculated by multiplying the age-sex specific

mortality rates of the reference population by the cumulative number of person-years in each stratum. The sum of all categories yielded the expected number of deaths. The SMR is the ratio of the observed number of deaths in our cohort to that of the expected number deaths based on the general population. An SMR >1 means excess mortality compared with the reference population. We calculated $95 \%$ confidence intervals (CIs) based on the Poisson distribution. 


\section{Data-analysis vascular events}

The risk for vascular events was assessed by survival analysis. Primary outcome measure was the composite event of death from all vascular causes (other than SAH), non-fatal stroke (other than $\mathrm{SAH}$ ) or non-fatal myocardial infarction (MI), whichever occurred first. Deaths from ischaemic stroke, intracerebral haemorrhage (ICH), MI, congestive heart failure and sudden death were classified as vascular death. Sudden death was defined as an unexpected death of presumed or proven cardiac origin occurring within 1 hour after onset of symptoms, or within 24 hours given convincing circumstantial evidence. Secondary outcome measure was the incidence of MI and stroke other than SAH. All events were classified according to pre-defined criteria.[4] Transient ischaemic attacks (TIAs) and recurrent SAH were not included as outcome events. We calculated the cumulative incidence of all vascular events at 5,10 and 15 years after SAH and compared this incidence with that of patients after TIA/minor ischaemic stroke. The TIA/minor stroke patients were derived from the LiLAC (Life Long After Cerebral ischaemia) study, in which 2473 patients with TIA/minor ischaemic stroke were followed for the occurrence of new vascular events (mean

follow-up 10.1 years).[4,5] With Cox regression analysis we calculated the age-and-sex adjusted hazard ratio (HR) of the vascular event risk in SAH patients compared with the LiLAC cohort. 


\section{RESULTS}

\section{Patients}

Between 1985 and 2001930 SAH patients were clipped and discharged alive; 154 did not meet the inclusion criteria. Of the 776 remaining patients 24 (3\%) could not be contacted. Therefore, for the SMR calculations 752 patients were included (66\% women, mean age 50 years; total follow-up 6064 patient-years, mean 8.1 years, range $0.2-20.1)$. For another $74(9 \%)$ patients information on vascular events was lacking. Thus, for the vascular event analyses 678 patients were included (total

follow-up 5525 patient-years). During follow-up 23 patients were censored because they moved abroad $(n=6)$ or were admitted to a nursing home for a non-vascular cause $(n=17)$.

\section{Standardized Mortality Ratios}

Of the 752 patients 107 died during follow-up. The overall mortality rate was $1.8 \%$ (95\%CI 1.42.1\%) per 1000 patient-years follow-up. Nine patients died suddenly before reaching the hospital. The other causes of death were cancer in 21 , recurrent SAH in 10, cardiovascular disease in 19 (11 of these 19 events fulfilled our pre-defined criteria for vascular event), other non-vascular diseases in 23 and unknown cause in 25. The overall SMR was 1.7 (95\%CI 1.4-2.1). The SMR was higher in women and seemed to decrease with increasing age (Table 1). 
Table 1. Standardized Mortality Ratios for SAH patients per different age and sex strata

\begin{tabular}{|c|c|c|c|c|c|}
\hline Stratum & No. patients & $\begin{array}{l}\text { No. patient- } \\
\text { years }\end{array}$ & $\begin{array}{l}\text { No. observed } \\
\text { death }(\mathrm{N})\end{array}$ & $\begin{array}{l}\text { No. expected } \\
\text { death }(\mathbf{N})\end{array}$ & $\operatorname{SMR}(95 \% \mathrm{CI})$ \\
\hline \multicolumn{6}{|l|}{ Men } \\
\hline$<40$ years & 62 & 305 & 1 & 0.3 & $3.2(0.5-23.3)$ \\
\hline 40-60 years & 138 & 1110 & 10 & 5.7 & $1.8(0.9-3.3)$ \\
\hline$>60$ years & 51 & 691 & 27 & 22.9 & $1.2(0.8-1.7)$ \\
\hline Total & 251 & 2106 & 38 & 28.9 & $1.3(0.9-1.8)$ \\
\hline \multicolumn{6}{|l|}{ Women } \\
\hline$<40$ years & 93 & 469 & 1 & 0.3 & $3.2(0.4-22.9)$ \\
\hline 40-60 years & 274 & 2027 & 22 & 5.7 & $3.8(2.5-5.9)$ \\
\hline$>60$ years & 134 & 1462 & 46 & 27.8 & $1.7(1.2-2.2)$ \\
\hline Total & 501 & 3958 & 69 & 33.8 & $2.0(1.6-2.6)$ \\
\hline \multicolumn{6}{|l|}{ All } \\
\hline$<40$ years & 155 & 774 & 2 & 0.6 & $3.2(0.8-13.1)$ \\
\hline 40-60 years & 412 & 3137 & 32 & 11.4 & $2.8(2.0-4.0)$ \\
\hline$>60$ years & 185 & 2153 & 73 & 50.7 & $1.4(1.1-1.8)$ \\
\hline Total & 752 & 6064 & 107 & 62.7 & $1.7(1.4-2.1)$ \\
\hline
\end{tabular}

No. observed death $=$ the number of patients who died during the follow-up time of our cohort No. expected death $=$ the number of patients expected to die during the follow-up time of our cohort based on population death rates 


\section{Vascular events}

In $62(9.1 \%, 95 \%$ CI $7.1-11.6 \%)$ of the 678 patients a vascular event had occurred: 27 patients had an ischaemic stroke, 10 an $\mathrm{ICH}, 16$ an $\mathrm{MI}$ and 9 a sudden death. The cumulative 5-year risk for vascular events other than SAH was $4.5 \%$ (95\%CI 2.8-6.1\%) and the cumulative 10-year risk $11.2 \%$ (95\%CI 7.0-14.4\%). The age- and gender adjusted vascular event rate in SAH patients was lower (HR 0.43, 95\%CI 0.33-0.57) than in TIA/minor stroke patients (figure 1). The HR did not change after adjustments for smoking and hypertension. 


\section{DISCUSSION}

SAH patients have an increased long-term mortality rate compared with the general population, especially women and young patients. In the first 10 years after SAH one of every nine patients experienced a vascular event other than recurrent SAH.

The cause of the excess mortality in SAH patients remains unknown. Previously, we found that the risk of recurrent $\mathrm{SAH}$ in clipped patients is 22 times higher compared with the general population.[1] The absolute risk, however, is relatively low (3.2\% in the first 10 years after SAH) and does not explain the excess mortality entirely. Another explanation is an increased risk of other vascular events. Detailed individual population based data on stroke or MI incidences are currently unavailable in the Netherlands. Some indirect comparisons with data from the literature, however, can be made. The incidence of stroke (ischaemic or haemorrhagic) in our cohort was 6.7/1000 patient-years while the incidence of stroke at the age of 50 in the Netherlands is $1.3 / 1000$ patientyears for men and 1.0/1000 for women.[6] Our incidence of all vascular events (stroke, death and MI) was 11/1000 patient-years while in a population of 91106 persons in Oxfordshire, this incidence in persons 55-64 old was 5/1000 patient-years for men and 4/1000 patient-years for women.[7] These indirect comparisons strongly suggest that the incidence of vascular events in SAH patients is higher than that in the general population. A last reason for the excess mortality might be an increased risk of infections and thrombo-embolic events during the first period of $\underline{\text { recovery after discharge from the hospital. }}$

Some limitations of our study need discussion. Firstly, information on vascular events was lacking for 98 patients. The majority of these patients had died or were not approached because they indicated in previous projects that they did not want to participate in future studies. Because death

or refusal of participation in research might be related to a worse health state, we might have underestimated the risk of vascular events. Conversely, 9 of the 62 patients with a vascular event 
other than SAH died suddenly presumably of cardiac arrest but we cannot completely rule out that some of them died of a recurrent SAH or of pulmonary emboli. Including these patients might have caused a slight overestimation of the risk of vascular events other than recurrent SAH. Secondly, we focused on patients who recovered to an independent state. Our results, therefore, apply only to patients discharged home or to a rehabilitation centre. In addition, we included only clipped patients. It is, however, likely that the risk of vascular events other than recurrent SAH is the same after coiling and clipping. Finally, because we used patients from a different study as comparison one might question if follow-up of patients and outcome events were handled the same. However, definition of outcome events was the same and investigators involved in the follow-up and the ascertainment of outcome events in the present study also participated in the same processes in the LiLAC study.

Because smoking and hypertension are risk factors for both recurrent SAH and other vascular events, all SAH patients should be stimulated to quit smoking and have their blood pressure regularly checked and treated if necessary. TIA patients are generally treated with cholesterol and blood pressure lowering drugs in combination with anti-platelet therapy. Whether similar secondary prevention is warranted in SAH patients needs further investigation. 


\section{FUNDING}

This study was supported by a grant from the Netherlands Organization for Scientific Research /ZonMw (grant 945-02-007). 


\section{REFERENCES}

1. Wermer MJH, Greebe P, Algra A, et al. Incidence of recurrent subarachnoid hemorrhage after clipping for ruptured intracranial aneurysms. Stroke 2005;36:2394-2399.

2. Feigin VL, Rinkel GJE, Lawes CM, et al. Risk factors for subarachnoid hemorrhage: An updated systematic review of epidemiological studies. Stroke 2005;36:2773-2780.

3. National life tables. CBS office of statistics Netherlands, Voorburg, the Netherlands.

4. van Wijk I, Kappelle LJ, van Gijn J, et al. Long-term survival and vascular event risk after transient ischaemic attack or minor ischaemic stroke: A cohort study. Lancet 2005;365:2098-2104.

5. A comparison of two doses of aspirin (30 mg vs. $283 \mathrm{mg}$ a day) in patients after a transient ischemic attack or minor ischemic stroke. The Dutch TIA trial study group. $N$ Engl J Med 1991;325:1261-1266.

6. Bots ML, Berger-van Sijl M, Jager-Geurts MH, et al. Incidence of cerebrovascular diseases in the Netherlands in 2000. In Jager-Geurts MH, Peters RJG, van Dis SJ, Bots, ML Cardiovascular diseases in the Netherlands 2006, disease and death rates The Hague: Dutch Heart Foundation 2006.

7. Rothwell PM, Coull AJ, Silver LE, et al. Population-based study of event-rate, incidence, case fatality, and mortality for all acute vascular events in all arterial territories (Oxford vascular study). Lancet 2005;366:1773-1783. 
Figure 1. The age and sex adjusted cumulative incidence of patients with a vascular event after SAH (pink line) and after a TIA or minor stroke (blue line)

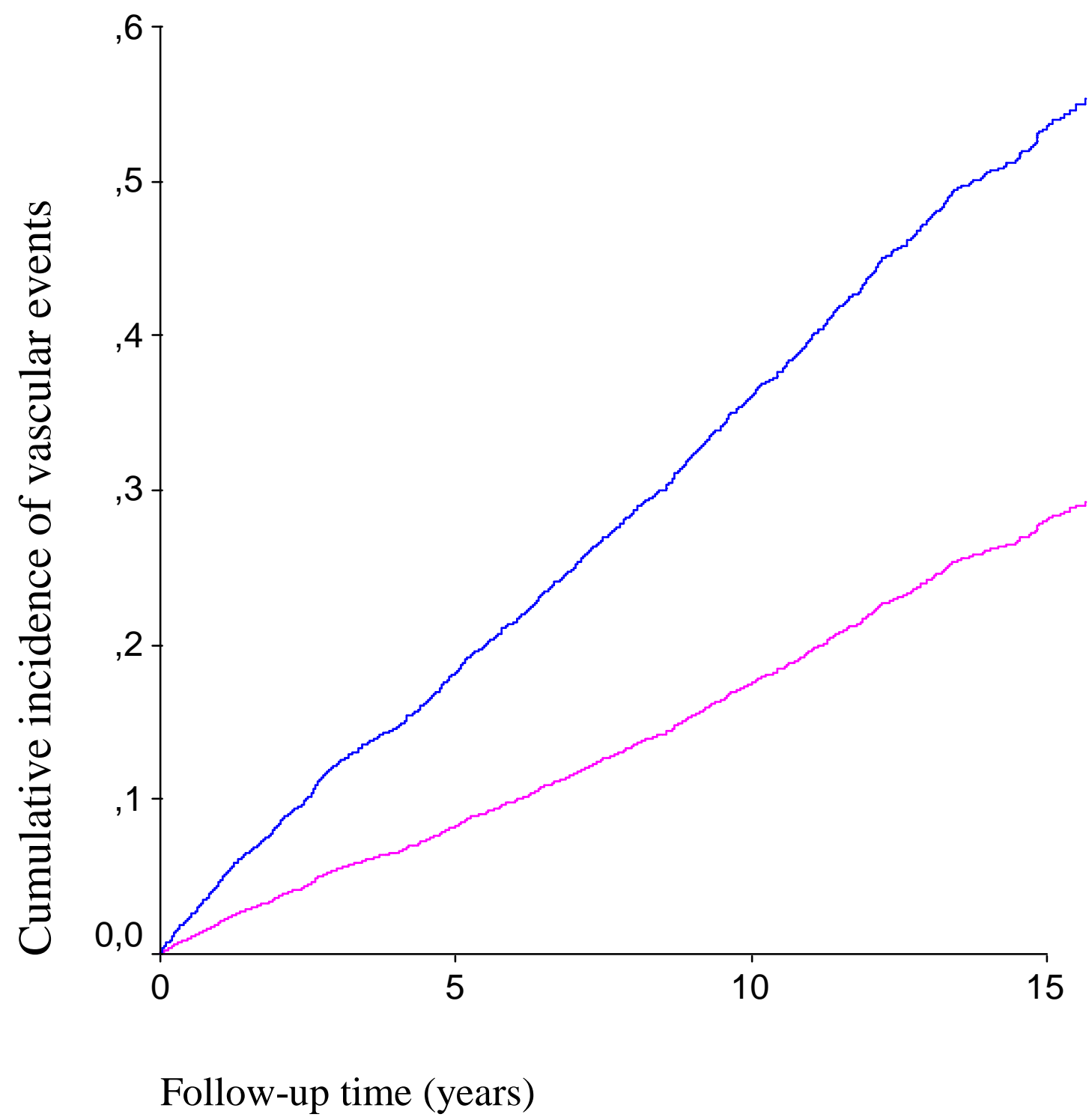

Patients at risk SAH

Patients at risk LiLAC
466

1768
226

1200
60

254 